\title{
A Decision Support Application in Tracking Construction Waste Using Rule-based Reasoning and RFID Technology
}

\author{
Lizong Zhang * \\ School of Information and Software Engineering, University of Electronic Science and Technology of China, \\ No.4, Section 2, North Jianshe Road \\ Chengdu, Sichuan 610054, China \\ Anthony S. Atkins \\ Faculty of Computing, Engineering and Sciences, Staffordshire University, \\ Beaconside, Stafford, Staffordshire ST18 OAD, United Kingdom \\ E-mail: a.s.atkins@staffs.ac.uk
}

Received 10 January 2014

Accepted 27 July 2014

\begin{abstract}
Protection of the environment is currently a high profile concern and this is resulting in more effective recycling and reuse of materials. This paper outlines a research project for developing and using a 'Technology Hub' framework combining Computational Intelligence - Rule-based Reasoning technology and Radio Frequency Identification (RFID) technology in the waste management sector. This framework has been developed using a case study based on a local waste recycling company. The project aims to help recycling companies in tracking, scheduling and intelligently handling incidents of waste movement in order to prevent fly-tipping and improve their management efficiency. Finally, the development procedure for a smart plasterboard waste management system is outlined, which includes a detailed discussion concerning the Rule-based Reasoning system design. This application provides a solution that a company can use to monitor the fleet/waste status and also generate decision support automatically in real time.
\end{abstract}

Keywords: Smart Waste Management System, RFID, Rule-based Reasoning, Technology Hub Framework

\section{Introduction}

The disposal of waste has become a sensitive topic in recent years in terms of the environment, health and economic cost. There are a number of government initiatives and environmental pressure groups seeking environmental, socially responsible, and economical means of future waste disposal. This paper outlines a research project on developing and using a 'Technology Hub' framework with Rule-based Reasoning and Radio Frequency Identification (RFID) technology in the waste management sector.

In general, waste is a combination of many types of material, and most of them are harmful and polluting. Plasterboard is an example where inappropriate disposal or fly-tipping could result in emission of hazard gas (i.e. $\mathrm{H}_{2} \mathrm{~S}$ ), which is odorous and can be dangerous in high

*E-mail: 1.zhang@uestc.edu.cn 
concentration $^{1-3}$. The UK generates more than $1 \mathrm{Mt}$ of plasterboard waste from the construction and demolition sector per annum, and only $7 \%$, or about 70,000 tonnes are recycled. It is anticipated that over the next 15 years the tonnage of plasterboard waste will increase because of expansion in its use and the rise in construction projects ${ }^{4}$. Most of the waste is handled by many small waste disposal companies, which normally provide their service in local areas. Therefore, improving the management and efficiency of waste disposal/recycling companies could help to reduce illegal disposal and improve the recycling rate for the entire country ${ }^{5}$.

In order to improve the environmental disposal of this type of waste, and prevent fly-tipping, a novel framework has been outlined ${ }^{6}$. The framework is designed to help local waste disposal companies improve their management efficiency, by providing authenticated transport records, scheduling and incident handling features ${ }^{7}$.

The research aims to solve a realistic problem for a small company by providing scheduling and real-time decision support features with minimising changes to their current procedures. Finally, a waste management system was developed based on a case study for a local Small-to-Medium Enterprise (SME) which processes plasterboard waste.

\section{Technology Hub Framework and Knowledge- based System Design}

In order to develop a plasterboard waste management system for local waste disposal/recycle companies, a Technology Hub framework is outlined. It focuses on the system structure and data flow in the system, and the relationship between each component. A knowledgebased system with rule-based reasoning technology is incorporated into the framework for automatically scheduling and handling unexpected events, i.e. the incident handling features ${ }^{8}$.

The proposed framework outlined in Fig. 1 consists of four layers, and it focuses on the data flow and functions of each layer. The first layer-'Data Collection' represents the data acquiring feature of the system. This layer acquires the data and information about the 'objects' in the physical world; in this waste management scenario, it is RFID technology. RFID technology is an ideal solution because it is able to provide a low cost and reliable identification function ${ }^{9,10}$. It has been widely used in many areas including waste management, but normally is for household waste and for identification of bins ${ }^{11}$.

The processing of raw data in this framework is a major task of the second 'Data Integration' layer. The third layer is the 'Knowledge Management' layer, which is responsible for generating logistical and tracking support including collection arrangements. This feature is supported by the adoption of a rule-based reasoning system. The last layer is 'Visualization'; it translates the result and the reasoning procedure to human readable text or diagrams, and is also responsible for delivering information with correct format to different types of terminals.

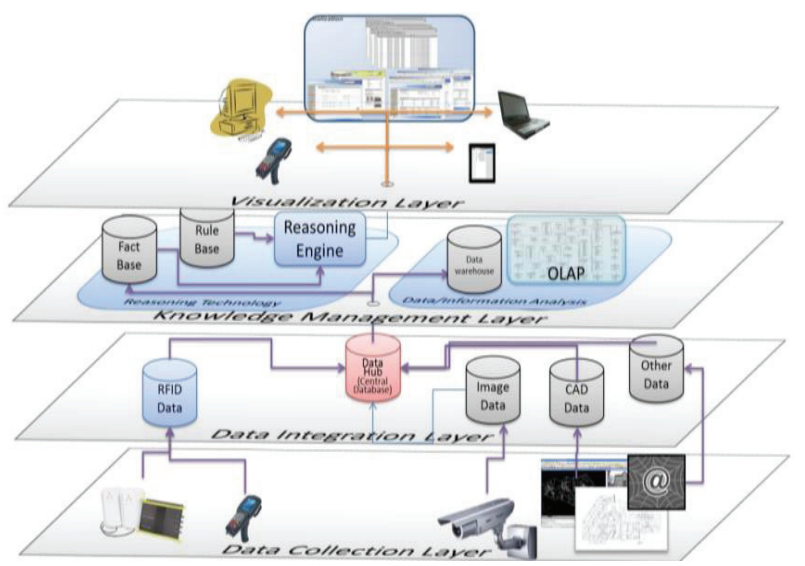

Fig. 1. Proposed Knowledge Hub Structure ${ }^{6,12}$

\section{Plasterboard Waste Management System- A Case Study}

A development procedure for smart waste management system development procedure is discussed based on a local SME waste disposal company. This company charges their customers for waste disposal and also makes additional profit by selling the recycled waste, such as plastic or card board. It allocates vehicles to pick up waste from their customers and deliver it back to its recycling centre. It contacts their customers to initially confirm the frequency of pickups, the waste type and volumes and vehicle/container types. This information is recorded in an MS Excel XLS file and the management team uses this file with no further digital/analysis feature linked to the existing system.

Two members of staff are engaged in arranging the collection schedules on a manual, daily basis. They are responsible for deciding the visiting sites of a vehicle based on their personal experience. The schedules are distributed to the operating staff at the start of their 
shift, and the sites visiting order is determined by drivers' personal experience.

This procedure initially worked satisfactory but with increased growth of the company, it is now experiencing difficulties. The two experienced staff can sometimes spend hours in re-scheduling their work due to changes in customer requests. Obviously, the existing work procedure of waste management is unable to match current workloads, which results in extra management cost, pickups delay and increasing labour costs.

In order to solve the practical problems of the company, there are two challenges raised in the application: firstly, the system should be able to detect the movement of vehicles. Secondly, the routing method should minimise changes to the pervious routing, as this is stipulated by the company. There are also two expected weaknesses of the design: (1) it is difficult to have the exact waste tonnage information during the collections, it can only be estimated by the driver with the help of the rule-based module via the application in their handheld device. (2) The detection of some 'incident' events relies on timestamp and the driver's report via a mobile application. Therefore, the 'incident' event type could be misjudged by the system before the drivers send their report.

\subsection{System Design}

The company needs to have an advanced management system to control and monitor their vehicle pickups. The requirements of the system need to balance the implementation cost and the system features. Several discussions were held with the company to determine their requirements of the system, which are as follows: (1) Tracking the waste movement; (2) Schedulingcreate waste pickups tasks for each vehicle; (3) Providing authentication for the waste disposal or recycling; (4) Handling incidents and provide suggestions.

In the initial trial of the smart plasterboard waste management System, the data capture technology used was RFID technology. The RFID equipment includes three components: reader, antennas and tags $8,12,13$. The layout of the waste management system is shown in Fig. 2; each reader has a wireless router for wireless connection to the system. Sites are connected by Virtual Private Network (VPN) technology via Internet connections.
Each object in the system is attached with one or more RFID tags; each tag contains a unique number, referred to as 'Tag ID'. The 'Tag ID' will be captured by the RFID equipment and sent back to the central server with other related information via the wireless network. The data sent to the server includes the RFID tag numbers, the antenna ID, the reader name, current time, Radio Signal Strength Indicator (RSSI) and tag type.

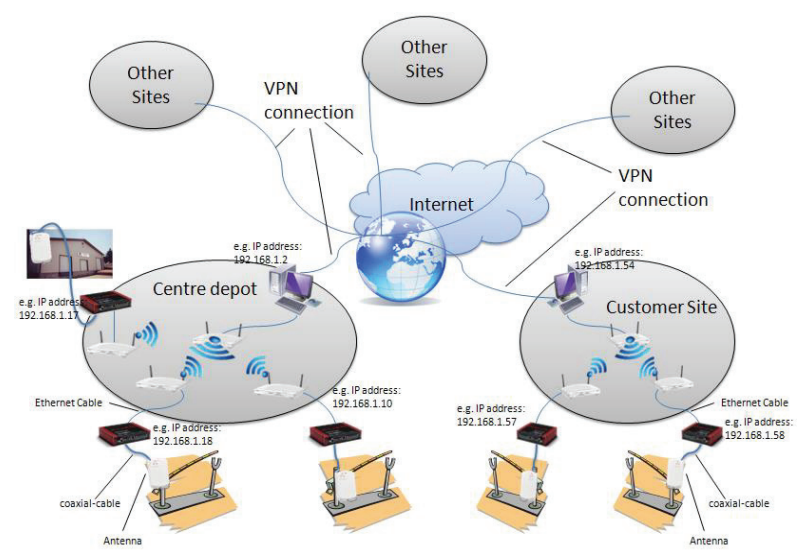

Fig. 2. Network Structure of the Hardware Components

In this system, Ultra High Frequency (UHF) RFID technology is used as it can provide up to 11 meters read range in an ideal environment ${ }^{14-16}$. However, UHF RFID signal is affected by metal objects. A method for reducing the effect is proposed: this is achieved by not directly attaching the RFID tag to the metal object surface and using a non-metallic material as a distance buffer (buffer thickness: $2 \mathrm{~cm}$ ). This approach can ensure the readability to about 3-6 meters, and it is sufficient for this application. Fig. 3 illustrates experiments for determining RFID reading range with large metal objects, in order to prove the feasibility of using RFID technology in waste tracking

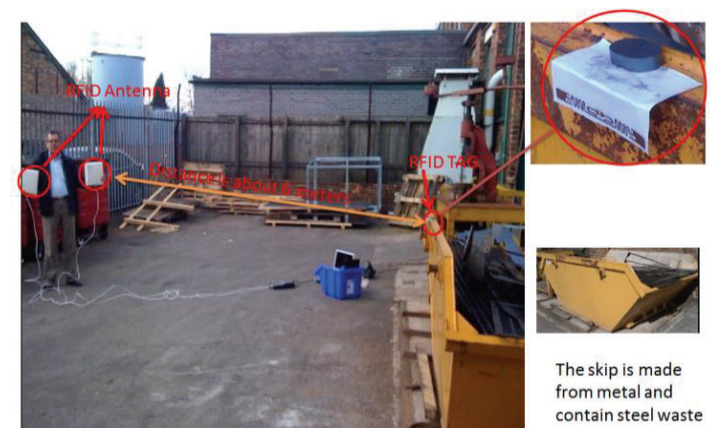

Fig. 3. Experiments for RFID Reading Range in a Large Metal Object Environment 


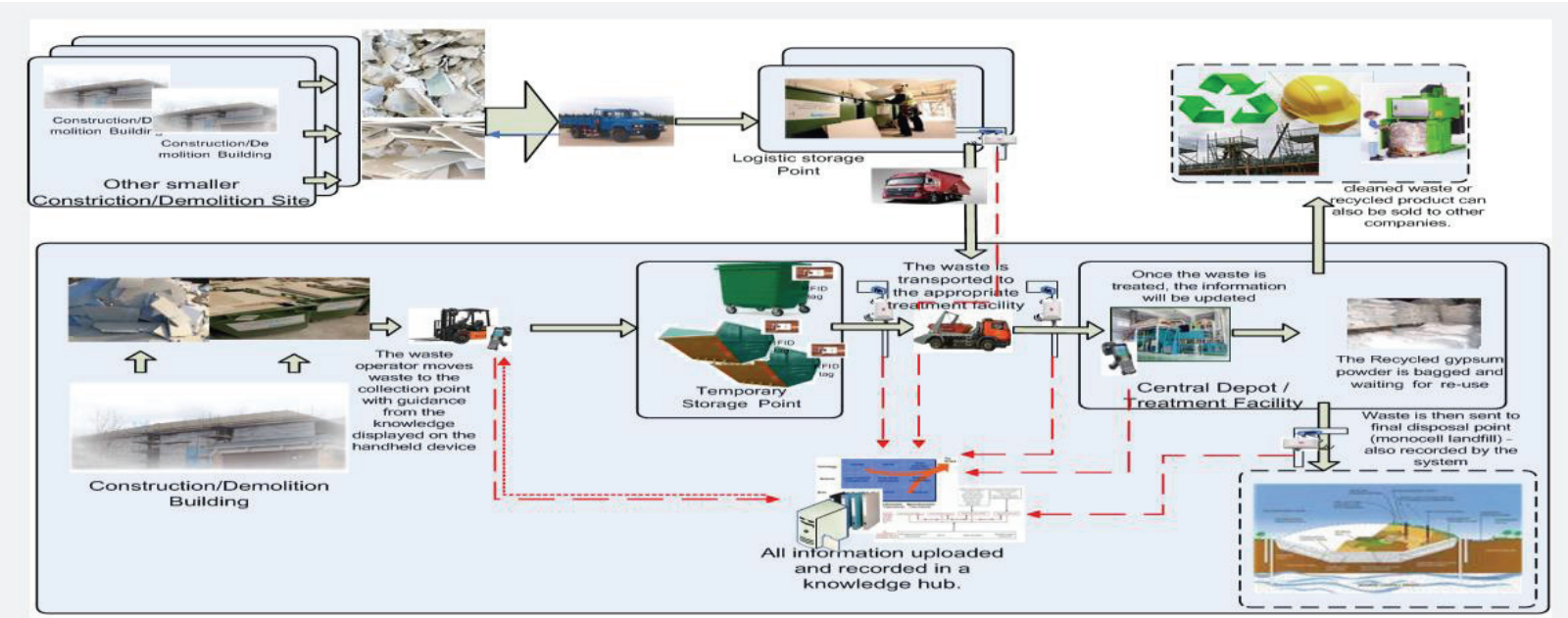

Fig. 4. Proposed System for Plasterboard Waste Management using RFID Technology and Knowledge Hub for Tracking and Verification Purposes

applications $^{17,18}$.

An overall system structure diagram is shown in Fig. 4. The design uses RFID technology to generate records including location, volume and weight, container movements and tracking inventories. It works with a knowledge-based system which could help managers to make decisions on scheduled logistics of waste to treatment plants and also provide the instruction for the operating staff to deal with the plasterboard and other kinds of waste.

\subsection{Implementation of Rule-based Reasoning Module}

The implementation starts from the knowledge collection. Rule-based reasoning technology is selected for this application. The reasons are (1) the company does not keep a full set of records, this makes casebased reasoning technology difficult to apply ${ }^{19}$, and (2) part of the knowledge provided by their staff is already incorporated in the production rule format.

There are three different types of reasoning existing in the system: schedule generation, incident handling and instruction. Each reasoning starts from creation of a unique Reasoning ID with a reasoning type to indicate the type of reasoning. The required facts and their values are then retrieved from the related database and placed into the entry. The reasoning chain can then be started to generate the desired results ${ }^{20-22}$.

\subsubsection{Schedule generation}

Initially a heuristic approach (min-max ant colony algorithm) for the scheduling problem was adopted.
However, the managers and drivers were unhappy with this approach, because sometimes there are substantial daily changes to vehicle routings, which can make problems for the operating staff and drivers, even though the routing result can be 'good' at petrol/time

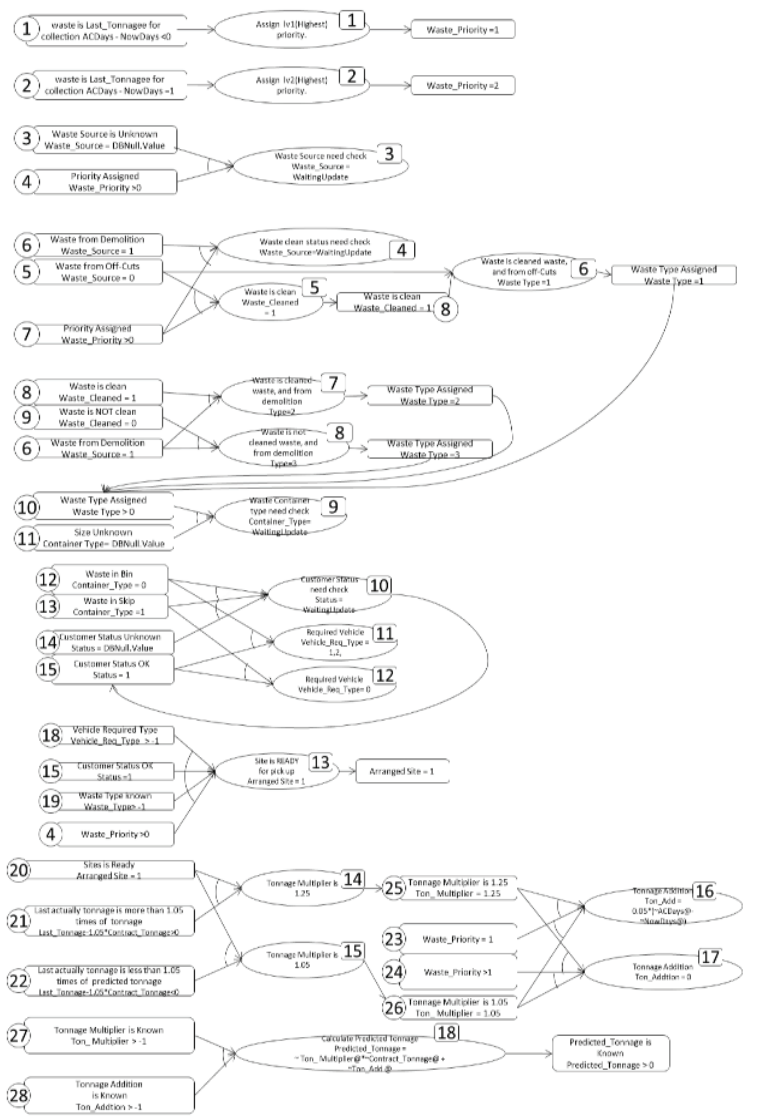

Fig. 5. Reasoning Chain of Generation the Schedule (First Step) 
Table 1. Example of facts used for step 1 schedule generation.

\begin{tabular}{|c|c|c|c|c|c|c|c|c|}
\hline $\begin{array}{l}\text { FACT } \\
\text { NAME: }\end{array}$ & $\begin{array}{l}\text { Reasoning } \\
\text { ID }\end{array}$ & $\begin{array}{l}\text { Reasoning } \\
\text { Type }\end{array}$ & $\begin{array}{l}\text { Collection } \\
\text { Frequency }\end{array}$ & $\begin{array}{l}\text { Contract } \\
\text { Starting } \\
\text { Date }\end{array}$ & $\begin{array}{l}\text { Contract } \\
\text { Finishing } \\
\text { Date }\end{array}$ & Site ID & $\begin{array}{l}\text { Site } \\
\text { Location }\end{array}$ & $\begin{array}{l}\text { Now } \\
\text { Date }\end{array}$ \\
\hline $\begin{array}{l}\text { EXAMPLE } \\
\text { VALUE: }\end{array}$ & 233 & 11 & 7 days & $\begin{array}{l}12 / \mathrm{Feb} / 20 \\
10\end{array}$ & $\begin{array}{l}12 / F e b / 20 \\
11\end{array}$ & 61 & $(564,232)$ & $\begin{array}{l}25 / \mathrm{Feb} / 20 \\
10\end{array}$ \\
\hline $\begin{array}{l}\text { FACT } \\
\text { NAME: }\end{array}$ & $\begin{array}{l}\text { Waste } \\
\text { Source }\end{array}$ & $\begin{array}{l}\text { Waste } \\
\text { Type }\end{array}$ & $\begin{array}{l}\text { Waste } \\
\text { Container }\end{array}$ & $\begin{array}{l}\text { Vehicle } \\
\text { Required }\end{array}$ & $\begin{array}{l}\text { Custamer } \\
\text { Status }\end{array}$ & $\begin{array}{l}\text { Last } \\
\text { Collection }\end{array}$ & $\begin{array}{l}\text { Predicted } \\
\text { Tonnage }\end{array}$ & $\begin{array}{l}\text { Contracted } \\
\text { Tonnage }\end{array}$ \\
\hline $\begin{array}{l}\text { EXAMPLE } \\
\text { VALUE: }\end{array}$ & 1 & o & & & 1-OK & 1300 & 1360 & $2000 \mathrm{~kg}$ \\
\hline $\begin{array}{l}\text { FACT } \\
\text { NAME: } \\
\text { EXAMPLE } \\
\text { VALUE: }\end{array}$ & $\begin{array}{l}\text { Arranged } \\
\text { Site } \\
1\end{array}$ & $\begin{array}{l}\text { Collection } \\
\text { priority } \\
2\end{array}$ & $\begin{array}{l}\text { scheduled } \\
1\end{array}$ & $\begin{array}{l}\text { Additional } \\
\text { Tonnage } \\
\text { o }\end{array}$ & $\begin{array}{l}\text { Remaining } \\
\text { Tomnage } \\
1360\end{array}$ & $\begin{array}{l}\text { Collection } \\
\text { successful. } \\
\text { o }\end{array}$ & $\cdots$ & \\
\hline & & & & & & & & \\
\hline FACT NAME: & Reasoning ID & $\begin{array}{l}\text { Reasoning } \\
\text { Type }\end{array}$ & Site Order & $\begin{array}{l}\text { Site Order } \\
\text { Reasoning ID }\end{array}$ & $\begin{array}{l}\text { Vehicle } \\
\text { Type }\end{array}$ & Vehicle ID & Waste Volume & $\begin{array}{l}\text { Number of } \\
\text { Skip }\end{array}$ \\
\hline $\begin{array}{l}\text { EXAMPLE } \\
\text { VALUE: }\end{array}$ & 23 & 3 & $1,5,4,7,3$ & $\begin{array}{l}231,243,233 \\
221\end{array}$ & o & 61 & 2400 & 1 \\
\hline FACT NAME: & Vehicle Capacity & $\begin{array}{l}\text { Remaining } \\
\text { vehicle } \\
\text { Capacity }\end{array}$ & $\begin{array}{l}\text { Next Site } \\
\text { Reasoning ID }\end{array}$ & $\begin{array}{l}\text { Next Site } \\
\text { Distance }\end{array}$ & $\begin{array}{l}\text { Next Site } \\
\text { Container } \\
\text { Type }\end{array}$ & $\begin{array}{l}\text { Next Site } \\
\text { Waste Type }\end{array}$ & $\begin{array}{l}\text { Total Sites } \\
\text { Reasoning ID } \\
\text { List }\end{array}$ & $\begin{array}{l}\text { Remaining } \\
\text { Sites } \\
\text { Reasoning ID } \\
\text { List }\end{array}$ \\
\hline $\begin{array}{l}\text { EXAMPLE } \\
\text { VALUE: }\end{array}$ & 2500 & 100 & 233 & 34 & 1 & o & $\begin{array}{l}231,243,233,221 \\
, 34,23,312,321\end{array}$ & ${ }_{1}^{34,23,312,32}$ \\
\hline FACT NAME: & $\begin{array}{l}\text { Total Sites } \\
\text { Location List }\end{array}$ & $\begin{array}{l}\text { Remaining } \\
\text { Sites } \\
\text { Location List }\end{array}$ & $\begin{array}{l}\text { Route Plan } \\
\text { Status }\end{array}$ & $\begin{array}{l}\text { Total cost } \\
\text { (distance) }\end{array}$ & $\begin{array}{l}\text { Visited Site } \\
\text { Number }\end{array}$ & $\begin{array}{l}\text { Current } \\
\text { Location }\end{array}$ & $\begin{array}{l}\text { Next Site } \\
\text { Location }\end{array}$ & $\begin{array}{l}\text { Reaming } \\
\text { Sites Waste } \\
\text { Information }\end{array}$ \\
\hline $\begin{array}{l}\text { EXAMPLE } \\
\text { VALUE: }\end{array}$ & $\begin{array}{l}(564,232), \\
(512,322), \\
(164,23), \\
(267,722), \ldots\end{array}$ & $\begin{array}{l}(564,232), \\
(512,322), \\
(164,23), \\
(267,722), \ldots\end{array}$ & o & 435 & 5 & $(0,0)$ & $(564,232)$ & $\begin{array}{l}23,12,32,22 \\
13,\end{array}$ \\
\hline FACT NAME: & $\begin{array}{l}\text { Remaining } \\
\text { vehicle }\end{array}$ & $\begin{array}{l}\text { Target } \\
\text { Vehicle Type }\end{array}$ & $\begin{array}{l}\text { Round } 2 \\
\text { Vehicle }\end{array}$ & Next Site OK & $\begin{array}{l}\text { Route } \\
\text { Waste } \\
\text { Type }\end{array}$ & & & \\
\hline $\begin{array}{l}\text { EXAMPLE } \\
\text { VALUE: }\end{array}$ & $6,7,8$ & & & o & & & & \\
\hline
\end{tabular}

cost. Thus, the heuristic approach was replaced by a Rule-based system because of the scheduling problems, in order to minimise changes in routing.

The procedure comprises of two steps of reasoning: the first step is to determine the sites needing to be visited in the next schedule, and the second step is to build the task of each route with allocated vehicles, customer sites and capacity information.

The scheduling process starts by determining the sites for the next collections, and the related facts are shown in Table 1. Some of the facts are retrieved from the contract database and others need their value to be obtained by reasoning. The first step of the reasoning is illustrated in Fig. 5. Once the sites' parameters are all assigned, the 'arranged site' fact will be given a value to indicate the site is ' $\mathrm{OK}$ ' and ready to be put into the schedule.

The second step is triggered by the updating of the sites list that needs to be visited in the next day. The routing generation procedure follows the 'knowledge' from the management staff. The reasoning engine creates an empty reasoning entry with the facts shown in Table 2. Once the sites information is updated, the reasoning then starts to generate the feasible path.

There are 26 Rules for the scheduling purpose: The reasoning procedures start from locating the first site, which is chosen from nearby sites randomly, and then the vehicle required is determined depending on the waste information of the site. The system then tries to locate the second site that is nearest to the first site and to match the vehicle type. The site will be considered priority if it appears on a previous schedule and on the same route as the first site. This procedure will be repeated until the vehicle capacity is full as illustrated in Table 2. The route is generated one by one, if one route is unable to add more or add any sites (i.e. the capacity of the vehicle is full), it will then be closed and a new reasoning initialised until there is no site waiting for a visit.

\subsubsection{Reasoning for incident handling}

Table 3 shows the facts used for the incident handling. The reasoning procedure is based on each route of the schedule. A reasoning entry will be automatically created in the Fact Base when a certain vehicle is detected leaving the central depot. The values of these facts are initialled from the Fact Base and the RFID system. The incident detection is based on the 'current time' and 'vehicle location': updating of the two facts will trigger a status check.

Once an incident is detected, the system will try to contact the driver/operating staff to confirm the incident. The uncertainty reasoning feature is also introduced in order to deal with the incident without a message from the driver. After the event type is decided and related information is updated, the engine will generate a solution for the events. A confirmation procedure will start after a certain time (e.g. 30 minutes) of the solutions being delivered. If no further details are updated, the system will assume the problem is solved; otherwise a new incident handling procedure will be started with the updated facts. 
Table 3. 'Facts' used for incident handling.

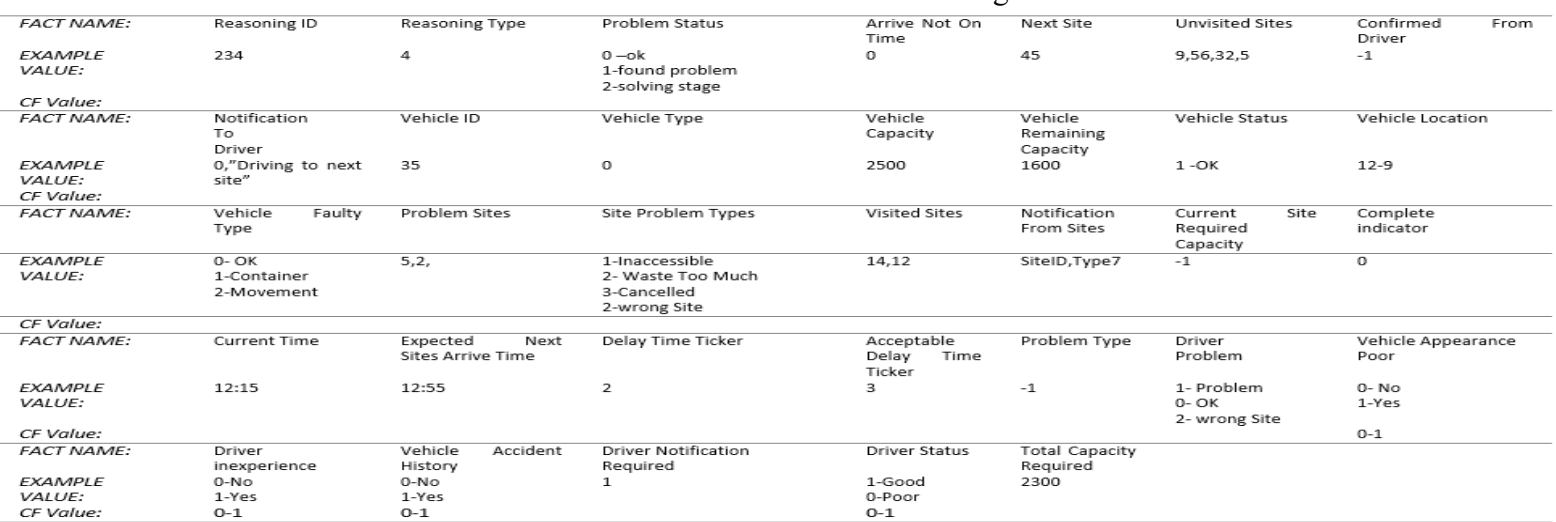

Table 4. 'Facts' used for instruction.

\begin{tabular}{|c|c|c|c|c|c|c|}
\hline $\begin{array}{l}\text { FACT } \\
\text { NAME: } \\
\text { EXAMPLE } \\
\text { VALUE: }\end{array}$ & $\begin{array}{l}\text { Reasoning ID } \\
336\end{array}$ & $\begin{array}{l}\text { Reasoning Type } \\
5\end{array}$ & $\begin{array}{l}\text { Reasoning Finish } \\
o\end{array}$ & $\begin{array}{l}\text { Site ID } \\
21\end{array}$ & $\begin{array}{l}\text { Site Location } \\
(231,213)\end{array}$ & $\begin{array}{l}\text { Vehicle Location } \\
21\end{array}$ \\
\hline $\begin{array}{l}\text { FACT } \\
\text { NAME: }\end{array}$ & Vehicle Type & Container & Site Waste Type & $\begin{array}{l}\text { Unvisited } \\
\text { Sites }\end{array}$ & Query Type & Message to user \\
\hline $\begin{array}{l}\text { EXAMPLE } \\
\text { VALUE: }\end{array}$ & 1 & 1 & 3 & 1 & 1 & $\begin{array}{l}0=\text { "Instruction } \\
\text { procedure finished } \\
\text { Finish Indicator }=1 ;\end{array}$ \\
\hline $\begin{array}{l}\text { FACT } \\
\text { NAME: } \\
\text { EXAMPLE } \\
\text { VALUE: }\end{array}$ & $\begin{array}{l}\text { User Concern } \\
1\end{array}$ & $\begin{array}{l}\text { Message } \\
\text { User } \\
1,1,3\end{array}$ & $\begin{array}{l}\text { Finish Indicator } \\
\end{array}$ & $\begin{array}{l}\text { Current Time } \\
13: 15\end{array}$ & $\begin{array}{l}\text { Instance } \\
\text { Time } \\
13: 10\end{array}$ & \\
\hline
\end{tabular}

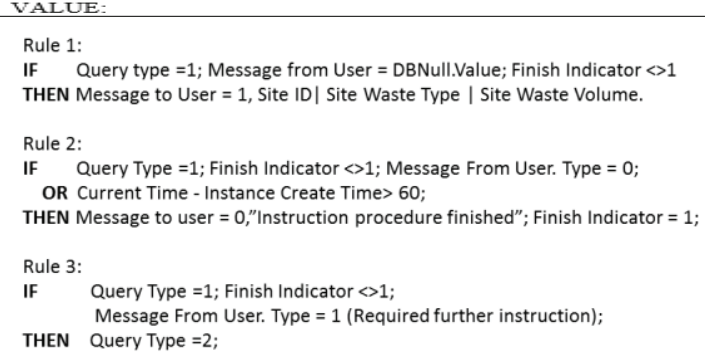

Rule 4:

IF Query Type =2; Message From User.Concern = 1 Finish Indicator $<>1$ THEN User Concern $=1$

Rule 5:

IF User Concern $=1$; Finish Indicator $<>1$; Site container type $=0$; site waste type 1 ;

THEN Message to User $=1$, Site ID $\mid$ Site Waste Type | Site Waste Volume, "Site keep cleaned waste using skip, Please do not mixed with other waste......."; Message From User=DBNull.Value; Query Type $=1$;

Fig. 6. Example Rules for Instructions Reasoning

\subsubsection{Instructions Reasoning}

In the trial stage, this feature is used to provide general information and the related knowledge will be expanded in later stages. The instruction reasoning procedure can be triggered by a vehicle arriving at a check point/destination (i.e. the vehicle location is updated) or requested by the operational staff, (typically for support in estimating waste tonnage). Table 4 illustrates the facts used for the instruction functions. The reasoning entry is not created until the request is issued by the system, and the background information such as vehicle location, vehicle type is then loaded to the reasoning entry.

When a vehicle arrives on site and all other reasoning is finished, an instructions reasoning instance is created with the facts shown in Table 4 . The first rule (Rule 1) shown in Fig. 6 is then fired by updating the fact 'query type $=1$ ' (triggered by vehicle arriving at a location). This rule will provide the waste type and predicted volume to operational staff. If a driver thinks the information to be sufficient, the reasoning instance will be closed at a certain time or from acknowledgement from the driver (Rule 2).

Otherwise, further information will be delivered by updating the 'Message From User' fact. The rest of the example rules in Fig. 6 are about a driver requesting future instruction about a waste issue: the sites uses skips for clean waste, and the simple instruction is 'not to mix with other waste' (Rule 5).

\subsection{Conflict Resolution Strategy}

The Rule-based Knowledge System requires that only one rule can be fired in each step. Consequently, a conflict resolution strategy must to be introduced in deciding which rule should be fired ${ }^{20}$. In this waste management application two conflict resolution strategies are introduced: The Longest Match Strategy and Under Certainty Factor Strategy. 
Under Certainty Factor Strategy, the rule with the highest combined $\mathrm{CF}$ of the conditions will be selected to fire, and if two or more rules have the same $\mathrm{CF}$, the longest match strategy is then applied only for these rules with same $\mathrm{CF}$, i.e. the rules with most conditions attached will be chosen. If the rules have the same CF, and the same quantity of conditions, then the latest rule will be selected. Certainty Factor can be used as conflict resolution strategy, but it was originally designed for uncertainty reasoning ${ }^{23}$. Consequently, the procedure of result generation is also different from the original 'certainty reasoning'.

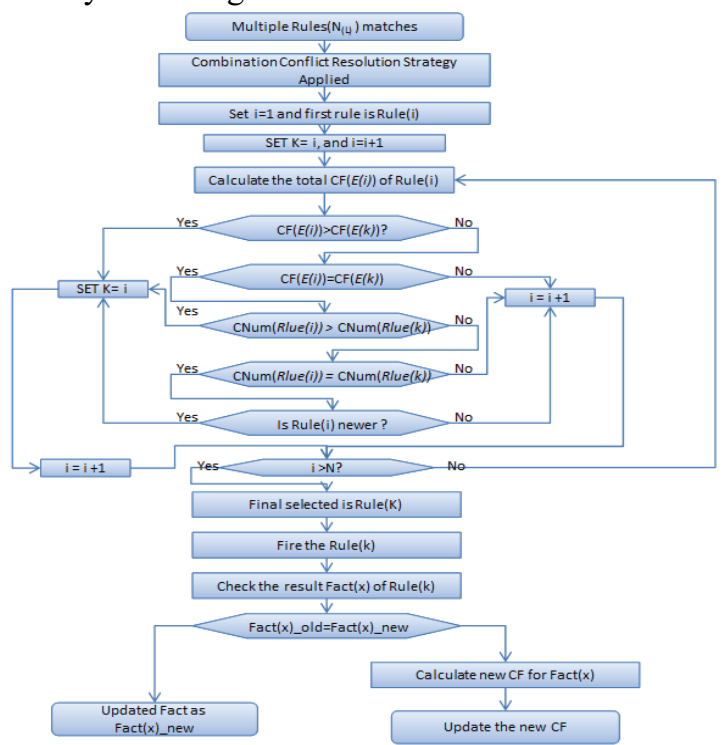

Fig. 7. Progress of the Conflict Resolution Strategy

The flow chart of the progress strategy is shown in Fig. 7. The conflict resolution process is triggered when multiple matched rules $\left(\mathrm{N}_{(\mathrm{L})}\right)$ are found during the reasoning. The system will evaluate each matched rule (Rule(i), $\forall i: i \in N)$ to find the max value of $\mathrm{CF}$ $(\max (\mathrm{CF}(E(i))))$. If the rules have same $\mathrm{CF}$ $(\mathrm{CF}(E(i))=\mathrm{CF}(E(k)))$, the quantity of rules' conditions is then measured for selection, and the rule with the most conditions will be select( $\operatorname{Max}(\operatorname{CNum}(R l u e(i))))$. In addition, if 'CF' and 'CNum' are both the same, the selection is based on the updated time of the rules, as the latest one will be chosen $(\mathrm{k}=\mathrm{i}$, when $\mathrm{CF}(\mathrm{k})=\mathrm{CF}(\mathrm{i})$ and $\mathrm{CF}(E(i))=\mathrm{CF}(E(k))$ and $\operatorname{Time}(\operatorname{Rule}(i))>\operatorname{Time}(\operatorname{Rule}(k)))$.

\subsection{Application Implementation and Results}

The implementation of the system consists of two aspects: the software and hardware aspects. The hardware aspect is concerned with the hardware installation including the network infrastructure and the RFID antenna location and/or the angle of the antenna. The software aspect mainly concerns the integration of the RFID system and the knowledge-based system.

\subsubsection{Implementation of software}

Integration of RFID technology with the knowledgebased system was not easy as a new knowledge-based system shell had to be developed. The current existing shells are mainly designed as individual knowledgebased systems and are difficult to integrate with other technologies. The data from the RFID system needs to be processed in order to generate the logistical records. The integration strategy used in this application is 'events trigger', which detects the events occurring first from the RFID data and then passes the identified events to the knowledge-based system module. The reasoning trigger procedure from detecting the tag is illustrated in Fig. 8. Once the event is identified by processing of the RFID data, the logistical records database is then updated if necessary, as some of events may only trigger the reasoning procedure.

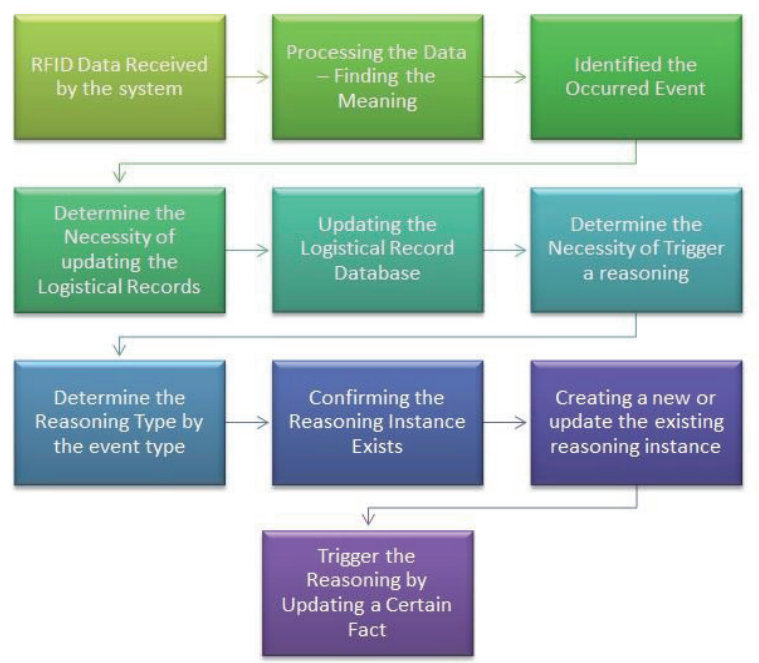

Fig. 8. Reasoning Trigger Procedure

The system then creates an instance or updates the related facts after confirming the reasoning type and the target reasoning instance. The fact updating is not only for a single instance, but for all activated reasoning instances that have matched reasoning types - the updating from an event may affect different reasoning types. 


\subsubsection{Hardware implementation}

The hardware implementation stage concerns the installation of the RFID equipment in the depot and at certain key customers' sites. In the proposed trial stage, the hardware installation is only for the depot sites and one or two customer sites. Two RFID antennas are installed at the main entrance of the depot on both sides (right and left) in order to determine the vehicles' arrivals and departures.

The tags are only attached to one side of the vehicle, and therefore, the system has the ability to determine the vehicle movement direction. The hardware installation is followed by the adjustment stage in order to achieve the optimal performance of the system. It is important to ensure the signal is strong enough to receive feedback from the tags.

The tags' performance could be affected by metal objects. From experimental work, a solution is outlined by using a buffer such as plastic or foam to keep 2-3 cm between the tags and the vehicle surface. Multiple tags are attached to an object: each vehicle has at least 3 tags attached on the left side, including the driver's window, in order to improve successful reading rate. The waste containers (the skips) also have multiple tags with one on each side (four sides in total) to ensure the object can be detected by the system.

\subsubsection{System operation procedures}

The system operation starts from the schedule generation. It is completed at mid-night of the day before, on a daily basis. The system loads the information from related databases, and generates the schedule for each vehicle.

The drivers are given their respective schedule when

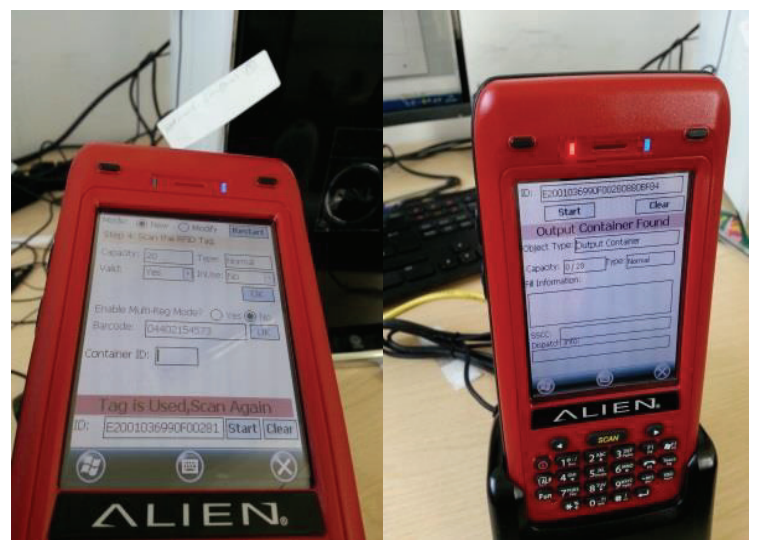

Fig. 9 Handheld Device and Application Interface their shifts start. Once the vehicle on the schedule passes the main gate (where RFID equipment is installed), the 'Incident handling' procedure is started, and the system will create a reasoning instance for each vehicle.

During the collection operation, the vehicles visit the sites in the order displayed on their lists and the arrival of the vehicles are reported to the management system by the RFID module. The larger sites are equipped with fixed RFID readers, and the vehicles are scanned automatically. Smaller sites do not have readers installed, instead, they are provided with RFID tags and the drivers scan the tag by using a handheld device to confirm the arrival. A mobile application was developed for communication with the central site and Fig. 9 shows the device and the application interface.

The exact weight of the load is measured at the central site which is equipped with a weighbridge. Thus, during the collection operation, the weight is based on the personal experience of the driver, or an 'instruction request' can be raised by the driver via the handheld device to assist in estimating the tonnage. In the meantime, imagery data (digital imagery of the waste) is taken as evidence of collection and disposal.

If a site has more waste than the expected tonnage (i.e. the scheduling module predicated weight based on previous data), and the vehicle is unable to collect all the waste, then, this situation is reported to the centre via the mobile application. The system receives this event and then triggers a reasoning instance with this fact from the event. Depending on the situation, for example the distance, waste tonnage, vehicle capacity or the weather, the solution could vary, and the driver could be asked to move to the next site and ignore this one, while a new vehicle is sent out for this site; or the driver is instructed to empty the vehicle at the centre first, and then return to collect at the site etc. Other incident events are handled in a similar manner.

\subsubsection{Results}

In order to verify that the system is able to generate schedules and track the vehicles, initially laboratory based experiments were conducted to demonstrate proof of concept. Then small scale experiments using the prototype system were conducted in a real SME company environment. 
The initial experiments were laboratory based using scaled remote radio controlled vehicles and a random set of pre-defined facts. Three check points were built with a RFID reader and 3 antennas. Two scaled vehicles were used to represent the waste transport/collect vehicles. Experimental results indicate the movement of the vehicle is completely $(100 \%)$ captured by the system and all designed functions can be successfully triggered. An example of the reasoning procedure is shown in Fig. 10.

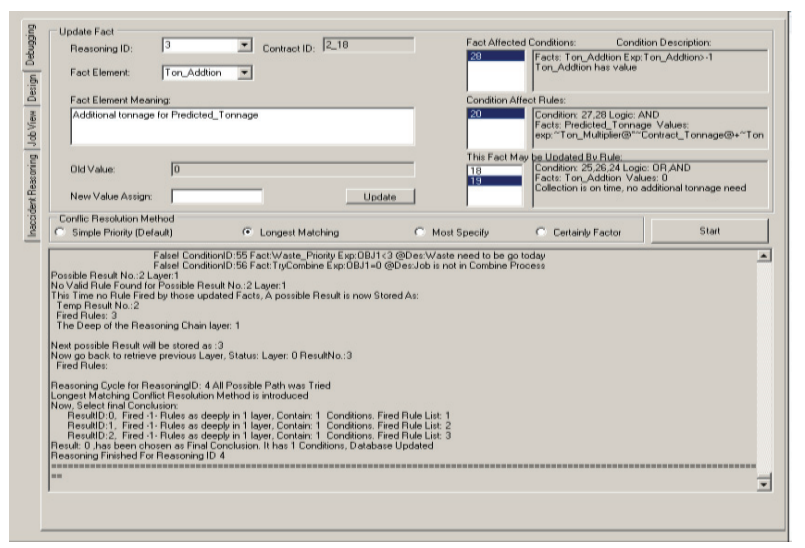

Fig. 10. Example of Reasoning Procedure Screen

Small scale experiments were then conducted. The experiments used 5 vehicles, but only the central site uses fixed RFID system, the participant customer sites are provided with RFID tags for scanning by the operational staff.

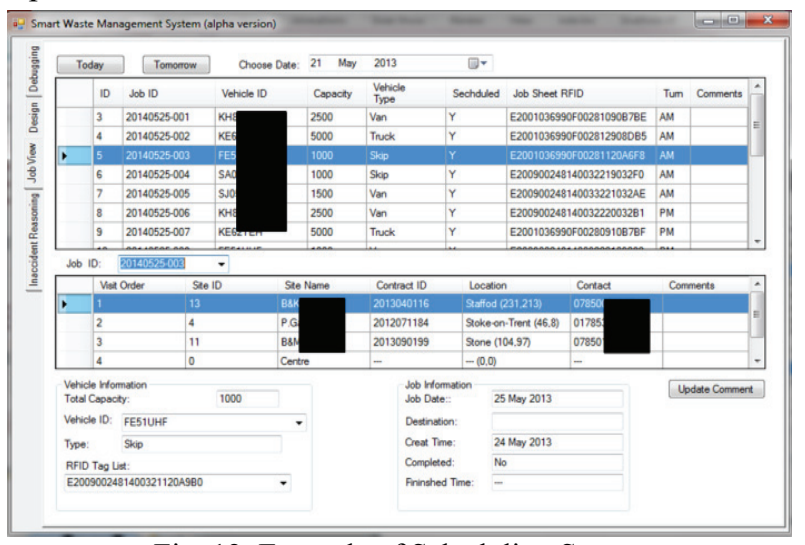

Fig. 12. Example of Scheduling Screen

Pervious schedules data of the 5 vehicles is initially inputted into the system in order to test the scheduling features. The result is shown in Fig. 12: the system successfully generated the schedule with minor changes. In this example, 3 of the routes have more than $50 \%$ similarity and only 1 route is different. The company staff evaluated the results and confirmed it was acceptable.

The incident handling features were also tested in these experiments as shown in Fig. 11, which shows a suggested solution for a fully loaded vehicle. These solutions are all provided in 2 minutes after the report is received from driver.

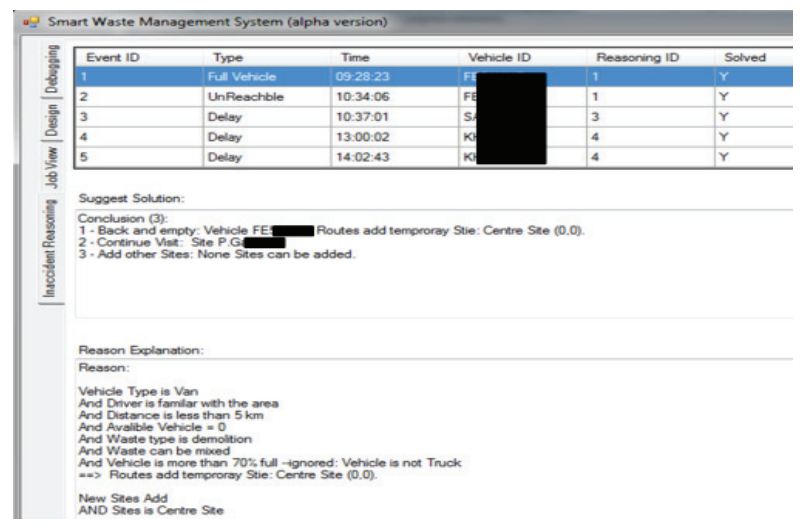

Fig. 11. Example of Incident Handling Screen

A survey of the management staff of the company was undertaken to gain their feedback. Table 5 shows our design is able to improve the company performance, typically in reducing scheduling and incident handling time.

Table 5. Feedback Results from Managers

\begin{tabular}{|c|c|c|c|}
\hline & Current Procedure & Our System & Improvement \\
\hline Scheduling Time & $<2$ Hours & $<10 \min$ & $92 \%$ \\
\hline $\begin{array}{l}\text { Scheduling } \\
\text { Result }\end{array}$ & Acceptable & $\begin{array}{l}\text { Acceptable(3) } \\
\text { or Better(1) }\end{array}$ & $\mathrm{n} / \mathrm{a}$ \\
\hline Running Cost & 2 Staff Salary & $\begin{array}{c}\text { Need a staff to check } \\
\text { occasionally, and } \\
\text { Tags }<£ 10 \quad(£ 0.05 \text { each })\end{array}$ & $>50 \%$ \\
\hline Installation Cost & $\mathrm{n} / \mathrm{a}$ & $\begin{array}{c}\text { Fix Reader and Handheld } \\
\text { Device } £ 4000\end{array}$ & $\mathrm{n} / \mathrm{a}$ \\
\hline $\begin{array}{c}\text { Incident } \\
\text { Handling Feature }\end{array}$ & $\mathrm{n} / \mathrm{a}$ & Good (4) & $\mathrm{n} / \mathrm{a}$ \\
\hline $\begin{array}{c}\text { Incident } \\
\text { Handling Time }\end{array}$ & $30 \mathrm{~min}-2$ hours & $<2 \min$ & $>90 \%$ \\
\hline Reliability & Normal & $\begin{array}{c}\text { Worse (1) } \\
\text { Normal (2) } \\
\text { Better (1) }\end{array}$ & $\mathrm{n} / \mathrm{a}$ \\
\hline Overall & & Good(4) & $>77 \%$ \\
\hline
\end{tabular}

\section{Conclusion}

A novel smart waste management system based on an SME waste recycling company using the proposed technology hub framework with Rule-based Reasoning technology and integrates RFID technology is discussed in this paper. The system has been developed following the proposed technology hub framework based on a case study of an SME company for improving its waste 
management efficiency from both vehicle scheduling and a real-time decision support aspect.

The design combines Rule-based Reasoning and RFID technology in order to enable the system to provide real-time decision support: RFID technology could detect vehicles or waste containers automatically without any unnecessary delay; and the Rule-based Reasoning with its knowledge base can improve the company's performance by providing decision support features - including scheduling and incident handling. The survey from management staff of the company clearly showed they are satisfied with the design and the system could improve the company's performance typically in reducing the scheduling and incident handling times.

\section{References}

1. DEFRA, Environmental impacts - priority products Plasterboard in, (Department for Environment, Food and Rural Affair, 2010).

2. F. Mcdougall, P. White, Integrated solid waste management a life cycle inventory, (Blackwell Sciences, Oxford, 2001).

3. E. A. McBean, F. A. Rovers, G.J. Farquhar, Landfill Gas Collection and Recovery, in: Solid Waste Landfill Engineering and Design, (Prentice-Hall, Inc., London, 1995).

4. DEFRA, Waste Strategy for England 2007, in, (Department for Environment, Food and Rural Affairs, 2007).

5. A. S. Atkins, L. Zhang, H. Yu, Issues in Environmental Recycling of Plasterboard Waste and Application of RFID and Knowledge Technology, in: International Conference on Software, Knowledge, Information Management and Applications (SKIMA), Co-sponsored by IEEE, (ISBN:9781851432516, March, Kathmandu, Nepal, 2008), pp. 54-59.

6. L. Zhang, A. S. Atkins, H. Yu, Chapter 10: Application of RFID and Mobile Technology to Plaster Board Waste in the Construction Industry, in: Designing and Deploying RFID Applications, (INTECH, ISBN: 978953-307-265-4, 2011), pp. 157-174.

7. L. Zhang, A. S. Atkins, H. Yu, RFID Technology in Smart Management System of Internet of Things in Construction Waste Logistics, in: 2nd International Conference on Management Science and Engineering (MSE 2011), (ISBN: 978-1-61275-994-4, Chengdu, China, 2011), pp. 193-199.

8. L. Zhang, A. S. Atkins, H. Yu, RFID Technology in Intelligent Tracking Systems in Construction Waste Logistics using Optimisation Techniques, in: 4th International Conference of Software, Knowledge and
Information on Management Applications, (Paro, Bhutan 2010).

9. K. Domdouzis, B. Kumar, C. Anumba, Radio-Frequency Identification (RFID) applications: A brief introduction, Advanced Engineering Informatics, 21 (2007) 350-355.

10. L. C. Wang, Y. C. Lin, P. H. Lin, Dynamic mobile RFIDbased supply chain control and management system in construction, Advanced Engineering Informatics, 21 (2007) 377-390.

11. M. A. Hannan, M. Arebey, R. A. Begum, H. Basri, Radio Frequency Identification (RFID) and communication technologies for solid waste bin and truck monitoring system, Waste Management, 31 (2011) 2406-2413.

12. L. Zhang, A. S. Atkins, H. Yu, Knowledge Management Application of Internet of Things in Construction Waste Logistics with RFID Technology, in: International Journal of Computing Science and Communication Technologies, (2012), pp. 760-767.

13. Auto-ID Center, $860 \mathrm{MHz}-930 \mathrm{MHz}$ Class I Radio Frequency Identification Tag Radio Frequency \& Logical Communication Interface Specification Candidate Recommendation, Version 1.0.1, in, (Auto-ID Centre, USA, 2002).

14. EPCglobal Inc., ЕРC ${ }^{\text {TM }}$ Radio-Frequency Identity Protocols Class-1 Generation-2 UHF RFID Protocol for Communications at $860 \mathrm{MHz}-960 \mathrm{MHz}$, (EPCgolbal Inc., 2008).

15. S. B. Miles, S. E. Sarma, J. R. Williams, RFID technology and applications, (Cambridge University Press, Cambridge, 2008).

16. G. Roussos, Networked RFID: systems, software and services, (Springer, London, 2008).

17. N. Choosri, L. Zhang, H. Yu, A.S. Atkins, Investigation of RFID Technologies for Fleet Management, (2009).

18. A. S. Atkins, L. Zhang, H. Yu, Applications of RFID and mobile technology in tracking of equipment for maintenance in the mining industry, in: 10th Australasian Coal Operators' Conference, (ISBN: 978-1921522-16-1, 11-12 February, Wollongong, NSW, 2010), pp. 350-358.

19. X. Xu, K. Wang, W.M. Ma, J. Lin, Improving the Reliability of Case-Based Reasoning Systems, Int. J. Comput. Intell. Syst., 3 (2010) 256-265.

20. M. Negnevitsky, Artificial intelligence: a guide to intelligent systems, 1st ed., (Addison-Wesley, Harlow, England; New York, 2002).

21. J. Durkin, Expert systems: design and development, (New York: Macmillan, ISBN: 0023309709., 1994).

22. J. C. Giarratano, G. Riley, Expert systems: principles and programming, 4th ed., (Thomson/Course Technology, Boston, 2005).

23. R. J. Schalkoff, Intelligent systems: principles, paradigms, and pragmatics, (Jones and Bartlett Publishers, Sudbury, Mass., 2011). 